education at - a provincial or foreign university. London University was for many years a theoretical University, simply on examining body; now, however, it is gradually blossoming forth into a practical or teaching one.

The concentration of the earlier professional studies will probably be one of the first developments of the new régime, and for this purpose a strong effort is being made to give practical effect to the recommendation of the Royal Commissioners appointed to consider the Charter in 1894. For this purpose steps are being taken to secure a site and funds to enable the Senate to establish an institute of medical sciences in the near neighbourhood of the University. The advanced studies will then be carried out at the various hospitals, which would then become veritable clinical schools.

It is to be hoped that we shall see Chairs of Medicine and Surgery endowed at the University, so that the prolessors who are appointed may be able to devote their whole energies to educational purposes.

In conclusion, I would remind you that the great element of success in professional life is the accumulation of experience. The experience can only be obtained by constantly applying yourselves to practical work.

If during your student days, and subsequently when you hold resident appointments, you make full and intelligent use of the countless opportunities which will present themselves of observing the course of disease, you will never repent the labour thus expended. You will thus early gain the confidence of your patients, and may it be said of you:

His years but young, but his experience old,

His head unmellow'd but his judgement ripe.

\section{UNIVERSITY OF MANCHESTER.}

By J. I.orrain Smith, M.D., Professor of Pathology in the University.

\section{ON THE STUDY OF PATHOLOGY IN MEDICAL} EDUCATION.

[ABSTRACT.]

THE decision which has recently been taken by the University to divide the Department of Pathology into two sections has been the direct result of the rapid growth of this subject in recent years. For a considerable period that department in this school has taken a leading place in bringing about the expansion of pathology, especially in its application to public health, and under the new arrangements Professor Delépine will continue his work in a department devoted to bacteriology and comparative pathology. To him will fall the duty of teaching students of public health, and he will at the same time be provided with the means of applying bacteriological methods of investigation to the problems which arise in public sanitary administration in Manchester and its neighbourhood. In this department, the direction of which bas been entrusted to my care, the student will receive instruction in general pathology and morbid anatomy.

A knowledge of the pathological changes in the human subject of disease retains all its importance for the student who intends to practise medicine, and this occasion affords a fitting opportunity for the consideration of pathology in relation to cognate subjects in the medical curriculum. In studying pathology the student finds himself in the same field as the clinician. The same subject is studied, but from a different point of view. The clinician studies the signs of disease and the mode of treatment with the purpose of discovering and applying the cure. When the study is carried a stage further, and the methods of physical science are applied to discover the nature of the changes in function and structure in the diseased tissues and organs the investigation becomes pathological

The ultimate unity of pathology and clinical medicine is clear, however, and it is futile to attempt to divorce them from each other. The pathologist must in due measure be familiar with clinical medicine, and the clinician must keep in his mind's eye the guiding lights of pathological research.

Pathology is ultimately an experimental science, but the study of disease must in the first instance pass through a preliminary stage in which the facts regarding its occurrence and form are merely observed. At this stage it is investigated in the hospital ward and in the post-mortem room. When sufficient knowledge has accumulated to give some clue to the cause of the disease the investigation is transferred to the laboratory. In the laboratory pathology is studied as a biological science. The facts and methods which the student has learnt in the earlier years of his course are applied to new problems, but no tissue is found in pathological structures that is not present in the normal body. No new chemical process is seen that has not been already exemplified in normal metabolism. In the laboratory, when the conditions are under our control, it is possible to study the obscure but all-important first stages of the process of disease.

It is in this way that pathology progresses as a science, and in order to master the subject a student must pass through a course of study which gives him the means of following the development of the ecience in all its stages. Pathology must be studied both in the hospital and in the laboratory.

Among the recent develnpments of pathology which call for the student's attention one of the mest striking is that of clinical pathology. This branch of pathology comprises observations on cases of disease in the making of which the observer acquires familiarity with laboratory methods and appliances. The best example is the clinical pathology of the blood. The blood is studied by chemical and microscopical methods in relation to almost every form of disease. We may learn, for example, not only the presence of bacterial infection in the circulation or in the tissues, but also the degree of resistance which is offered to the invasion. We may further find in these phenomena the clue to the principles of treatment. Again, the study of malaria and allied conditions resolves itself into a microscopical study of the blood. Similarly, the large group of diseases affecting the constituents of the blood is studied by the methods of clinical pathology. This branch of the science is daily increasing in importance, and requires the most earnest attention of the student. It is most appropriately studied in relation to cases in the hospital wards.

When we turn to the study of pathology as a natural science we have to consider its relation to the sciences with which the student has become acquainted in the earlier years of his cru se. During the period in which a student is working at these sciences be ought to be forming in his mind the standards according to which his life-work is to be carried out, but it is the unfortunate experience of teachers to find that often relatively little permanent benefit has been derived from this early discipline. This results from the hurried way in which the subjects are taken up and dismissed one after the other. When the inevitable examination is passed the knowledge which a student has acquired is often rapidly lost, and there is too little result for the amount of work done. The present curriculum is crowded with disjointed subjects. Some process of conservation is required to prevent the dilapidation of knowledge.

It was formerly the custom of Examining Boards to examine the student, when he came up for his degree, in the earlier as well as in the later subjects of the curriculum. This mode of conserving the student's knowledge has become impossible, but no means have jet been discovered to effect the purpose of this old regulation.

The study of pathology as an experimental science in the final period of the medical curriculum to a certain extent prevents the educational waste to which I have referred. In the recent study of immunity under the guidance of Ehrlich, of the pathology of inflammation as it has been taken up by Metchnikoff, or of cancer as it has been explained by Farmer, we find ready illustrations of the way in which pathology keeps alive in the student's mind this physiological, biological, and botanical knowledge which he has already acquired. The study of pathology might hecome more valuable in this respect were it possible to teach the student the subject by introducing him directly to research. It is difficult to see how this could be done with the average student. He has neither the time nor the experience required for profitable work at research. Students who take special courses and post-graduate students do find it possible, and it is to them of inestimable value. The case of the average student is to some extent met by practical teaching. This is, however, only a partial solution of the difficulty. Practical teaching lacks the stimulus to spontaneous observation which is characteristic of research, nor does it provide the same incentive to conserve and use the knowledge derived from cognate sciences. The impulse to pathological research arises not only from the intellectual desire to pursue the scientific investigation of the subject, but also from the practical demand for the means to break the power of disease.

The student who masters pathology in all its aspects, and who is able to apply all the learning of the schools in his 
daily work of preventing the ravages of disease, will often wonder that knowledge so important and so desirable is so difficult to attain. Our immediate perceptions do not carry us very far, but to investigate the facts and processes which lie beyond the reach of our immediate senses we can apply the experimental method. Patient investigation by this method gradually adds to the sum of our knowledge. There is no ground for pessimism. We must pass through the earlier stages before we reach the later ones. Many of the conclusions to which we have now come may require to be modified, but further progress is possible only because we have already reached the present stage. We cannot adopt the views of the distinguished President of the British Association for the Advancement of Science, who remarked in his opening address that "the beliefs of all mankind about its material surroundings are not only imperfect but fundamentally wrong." Still more depressing is his explanation of this circumstance: "Presumably, however, this is either because too direct a vision of physical reality was a hindrance and not a help in the struggle for existence, because falsehood was more useful than truth, or else because, with so imperfect a material as living tissue, no better results could be obtained." To discuss what is meant by the phrase "direct vision of physical reality" would involve us in metaphysics. It is sufficient to know that it is a method of knowledge which is denied to the scientific investigator. The far-reaching discoveries which occasioned $\mathrm{Mr}$. Balfour's remarks do not differ from the former results and discoveries of physical science. They have been reached by the same methods as those applied in the earlier stages of the science, and by these methods the progress of the science will still continue.

The announcement of a far-reaching discovery in any of the natural sciences is hardly a fitting opportunity for proclaiming the defects of the scientific method. It remains, rather, for investigators to continue their work with a yet firmer assurance, persuaded that scientific knowledge does not suffer som defects which it is their duty to eliminate.

\section{UNIVERSITY COLLEGE, LONDON.}

By Norman Collie, Ph.D., F.R.S. Professor of Organic Chemistry, University College.

\section{THE RELATION OF CHEMISTRY TO MEDICINE.} ABSTRACT.

In dealing with the subject, the relation of chemistry to medicine, it is quite impossible in an address to do more than merely touch on the many important relations of chemical science to that of medicine. Even in the earliest times, the manufacture of drugs, the production of new ones, aiso many of the theories explaining the physiological action of medical compounds, were all largely due to chemists. Nowadays, owing to the enormous progress in science, it is more than ever imperative that the medical man should be able to follow much of the work being done in chemical laboratories. In former times, the alchemist during his search for the philosopher's stone or the elixir vitae was always producing new substances; these, although they did not fulfil the desired aim, yet served in the hands of the physician often as valuable drugs. Again, the chemist by his analytical methods helped medicine largely in many ways, testing, purifying, and improving drugs and foods.

Although the Egyptians possessed a considerable knowledge of both chemistry and medicine, it was not till the eighth to the tenth century that there is any historical connexion between the two. The Arabians at Bagdad, and the Moors at Cordova established universities famous throughout the civilized world. Public hospitals and libraries of vast size for the study of diseases and the preparation of medicines existed, and students flocked there from all Europe. The materia medica of the Arabians consequently being a great improvement on that of the Greeks and Romans. The chief writer of that date was Avicenna, most of whose chemical ideas were borrowed from the Arabian chemist Geber. After the decay of the power of the Moors in Spain there was no further progress for several centuries. Early in the fourteenth century an alchemist, Basil Valentine, benefited medicine by bringing into use antimony salts: his writings, however, are extremely obscure. At the end of the sixteenth century was born a man whose writings revolutionized both chemistry and medicine. Paracelsus, a man in many ways most contemptible, zet was one of those who have lelt their mark in history. It was Paracelsus who raised the latent erergies of the human mind that had been torpid for so many centuries. He advocated the importance of chemical medicines and of chemical investigations to the physician As a result a vast collection of new drugs were prepared and tried. Some of these were better and some of these' were worse than the medicine of the Galenists. After Paracelsus the ideas promulgated by van Helmont and the Iatrochemists produced another revolution in both medicine and chemistry. These ideas, which were a mixture of deductions drawn from the chemical facts of those days, of spiritualism and of a vast number of wild theories and speculations, ruled supreme in the medical world; till Robert Boyle, towards the end of the seventeenth century, was Iargely instrumental in overturning these absurd doctrines by means of a lengthy treatise called the Sceptical Chemist.

After Boyle's time, for almost a century the chemical, and through it the medical, horizon was darkened by another erroneous theory : the Phlogiston Theory. Also in the meantime chemical knowledge was getting more out of touch with that of medicine. The discovery towards the end of the eighteenth century of the most common of the vegetable acids by Scheele, and later the isolation of many of the pure active principles of plants were valuable to the physicians. But in those days the chemist was engaged chiefly on facts dealing with the atomic theory and the ultimate constitution of matter: the question as to the constitution or the molecular composition of starches or of albumens, or the nature of the action of ferments : these were entirely beyond his powers. In fact, even at the present time the chemist is the first to admit that the chemistry of the living plant or animal is by far the most difficult and at the same time one of the most fascinating problems of the science.

The chief discoveries in chemistry during the last half of the nineteenth century that have a bearing on medicine are extremely numerous. Anaesthetics, antiseptics, new drugs, are some of the more obvious. Indirectly, the work of Fischer on the sugars is also of interest. Not only has he produced synthetically grape and fruit sugar, but he has also made a large number of artificial sugars. Most of these he has found to be undecomposed by such ferments as yeast. Again, others are decomposed by ferments more rapidly, and are probably of more value as foods; and as the sugars and the allied starches are the most important of all foods (albuminoid substances excepted), their chemical investigation is of the highest importance to the medical man. This question of the action of ferments must ultimately be answered by the chemist, and, as these processes of fermentation are largely connected with vital phenomena, their significance cannot be overrated.

The physiological action of toxins and antitoxins has for some time largely engaged the attention of medical science, but it will probably be the chemist, after he has determined their molecular structure, that will be able to explain how and why they are produced. In the process of the assimilation of food the changes that occur are purely chemical. The composition of the various secretions, also, can only be arrived at by an anajysis in a chemical laboratory. The composition of the excreta is also of the utmost importance in diagnosing whether the living machine is in proper working order, and whether each particular organ is producing its own proper waste products. In every case the chemist must be consulted; he may be a pathological, a physiological, or a pure chemist. Physicians, the scientific representatives of practical medicine, to be eminently successful in their prof $\in$ :ssion must without doubt be able to understand the general aims and objects of these various branches of chemistry, and this they are unable to do unless they have at least mastered the elements of the science. 'In the case of specialists it is even more necessary, for the human body is the most wonderful laboratory in existence. In it the raw material is changed to the most complex products. These in turn are used for their proper purposes, thrown aside, and finally got rid of. It is the province of the physician to keep this marvellous laboratory in working order; but how is this possible should he be ignorant of the general methods of how these changes go on? It is useless to expect that by merely oiling a motor-car the effects of using bad petrol or of defective sparking can be eliminated. Obviously, therefore. the medical man who is able to understand the bearing of chemical research on the problems connected with this human laboratory is far more competent to direct the working of it, than one who is ignorant of these chemical investigations, for he has a wider horizon, more knowledge, consequently greater power. 